\title{
Early Sound Patterns in the Speech of Two Brazilian Portuguese Speakers*
}

\section{Elizabeth Reis Teixeira}

Universidade Federal da Bahia, Brazil

Barbara L. Davis

University of Texas at Austin

\begin{abstract}
Key words
Abstract

acquisition

Sound patterns in the speech of two Brazilian-Portuguese speaking children are compared with early production patterns in English-learning children

ambient effects as well as English and Brazilian-Portuguese (BP) characteristics. The relationship between production system effects and ambient language influ-

phonetic ences in the acquisition of early sound patterns is of primary interest, as English and BP are characterized by differing phonological systems. Results

production emphasize the primacy of production system effects in early acquisition, although even the earliest word forms show evidence of perceptual effects speech from the ambient language in both BP children. Use of labials and coronals and low and midfront vowels in simple syllable shapes is consistent with acquisition data for this period across languages. However, potential ambient language influences include higher frequencies of dorsals, use of multisyllabic words, and different phone types in syllable-offset position. These results suggest that to fully understand early acquisition of sound systems one must account for both production system effects and perceptual effects from the ambient language.
\end{abstract}

\section{Introduction}

Full understanding of the nature of speech acquisition requires exploration of both production and perception factors. Jakobson (1968) proposed the universal primacy of perceptual factors in the systematic development of a child's production repertoire. Subsequent studies have refuted his claim of a universal developmental sequence (e.g., Macken, 1992). Recent work has emphasized the importance of child-internal production factors for understanding characteristics of speech acquisition in the prelinguistic and early word period (e.g., Davis \& MacNeilage, 1990, 1994, 1995; Davis, MacNeilage, \& Matyear, 2002; Locke, 1983). Production oriented views emphasize consistencies in sounds and sequences

* Acknowledgments: This work was supported in part by Fundação Coordenação de Aperfeiçamento de Pessoal de Nível Superior (CAPES) to the first author and by a National Institutes of Health Grant R01 HD2773 to the second author.

Address for correspondence: Elizabeth Reis Teixeira, Universidade Federal da Bahia, Instituto de Letras, Programa de Pós-Graduação em Letras e Lingüística, Rua Barão de Geremoabo, nº147 CEP: 40170-290 Campus, Universitário-Ondina, Salvador-Bahia; e-mail: <ereist@ufba.br>. 
across languages, suggesting that movement sequences rather than perceptual factors are constrained in children and are the predominant influence on the early production repertoire (Davis \& MacNeilage, 2000). Primacy of child internal production factors would predict similarities across children learning different languages. In contrast, developmental differences in children related to the characteristics of their ambient language suggest the importance of perceptual factors based on the salience of the particular language environment.

Analysis of children's patterns of phonetic productions without reference to the targets they might be attempting emphasizes the phonetic substrate that the child brings to the task of speech production. Most studies of phonetic production patterns without reference to accuracy of production are of prelinguistic babbling or the early single-word period. A goal of this study was to begin to understand the ways in which these early phonetic patterns may be retained or resolved across a longer period of speech acquisition than the single-word period.

Analysis of phonetic characteristics of children in diverse language communities allows exploration of both similar patterns across languages predicted from a production view and differing patterns predicted by perceptual effects from a particular ambient language. Proposals regarding the generality of production influences, largely based on studies of English-speaking children, need to be replicated by careful study of children in a variety of language communities. Large databases, which allow quantitative analyses for evaluation of early production data, rather than reliance on anecdotal exemplars, have been emphasized in recent acquisition studies (e.g., Gildersleeve-Neumann, 2001). Accordingly, this study focuses on phonetic patterns in two typically developing children in a Brazilian Portuguese (BP) language community across the period of single-word and early word combinations. The goal of this study is to assess the generality of production regularities in this period of acquisition versus potential ambient language influences.

\section{1}

\section{Early production patterns}

Studies of speech acquisition largely based on studies of English have shown that sound types and sequences produced by children in the babbling and early word period are similar (Locke, 1983; also see Vihman, 1996 for a review). Generally, children are described as producing labial and coronal, stop and nasal consonants (Boysson-Bardies \& Vihman, 1991; Davis \& MacNeilage, 1995; Roug, Landberg, \& Lundberg, 1989; Stoel-Gammon, 1985). Low or mid front and central vowels (Davis \& MacNeilage, 1995; Lieberman, 1980) predominate. Monosyllables are far more frequent than disyllables or polysyllables (Davis \& MacNeilage, 1995; Kent \& Bauer, 1985; Oller \& Eilers, 1982; Vihman, Ferguson, \& Elbert, 1986; Vihman, Macken, Miller, \& Simmons, 1985). Few dorsals (Stoel-Gammon, 1985) and few fricatives, liquids and affricates (Gildersleeve-Neumann, Davis, \& MacNeilage, 2000; Locke, 1983) are found in babbling or early words.

The importance of the relationship between consonants and vowels both within and across syllables has also been emphasized in recent studies (e.g., Davis \& MacNeilage, 1994, 1995; Davis et al., 2002; MacNeilage, Davis, \& Matyear, 1997). In these studies, rhythmic mandibular oscillation accompanied by phonation is proposed as an underlying principle motivating both intra- and inter-syllabic characteristics of babbling and 
early speech (MacNeilage \& Davis, 1990, 1993). Intrasyllabic patterns are seen as emergent properties of rhythmic mandibular oscillation with lack of independence of tongue movement from jaw close-open movements within syllables. Three consonant vowel cooccurrence properties are predicted: (1) labial consonants with central vowels; (2) coronal consonants with front vowels; and (3) dorsal consonants with back vowels. The tongue position of the initial consonant closure sets the vocalic portion of the syllable. For labials, with no tongue involvement in consonant closure, the open portion results in a central vowel. For both coronals and dorsals, the position of the tongue in the closure phase affects the vowel quality in the open portion; front vowels co-occur with coronals and back vowels with dorsals. Trends consistent with these predictions have been found in quantitative analysis of large databases (i.e., over 1000 syllables per child). Davis \& MacNeilage $(1994,1995)$ studied seven English-learning children during the babbling period and 10 English-learning children during the first-word period (Davis et al., 2002). In addition, intrasyllabic regularities have been found in analysis of firstword data from Japanese, French, and Swedish infants in the Stanford database (data courtesy of M. Vihman), in seven Quichua-learning infants (Gildersleeve-Neumann, unpublished dissertation). One Italian-learning infant (Zamarich \& Lanni, 1998) showed the intrasyllabic labial/central and coronal/front patterns in the first-word period. Confirmation of these regularities in a variety of language communities suggests broadly general patterns that may be typical of children in early speech acquisition. These regularities are seen as being based on production system effects of primacy of jaw movement over tongue independence within earliest intrasyllabic CV sequences.

Reduplication (i.e., /baba/ or /dædæ/) is the predominant intersyllabic pattern in early sequences. For variegated sequences, mandibular oscillation results in height changes predominating over front-back changes for vowels and manner over place changes for consonants. (Jaw movement accounts for height changes and the tongue for front-back changes across utterances; Davis \& MacNeilage, 1995.) An additional facet of intersyllabic sequencing has also been noted in recent studies of the first word period. Although, variegated consonant disyllables show a strong effect whereby labial-coronal $(\mathrm{L}+\mathrm{C})$ sequences in consonant variegation are the major type of variegated sequence for place of articulation (MacNeilage, Davis, Kinney, \& Matyear, 2000b). This effect has been interpreted as a "start easy — end hard" principle, whereby the child initiates vocal production with a labial closure requiring only jaw oscillation and follows with a tongue gesture once the system is in operation. This sequence effect has also been noted in a study of 10 languages (MacNeilage et al., 2000b) and interpreted as an extremely fundamental property of languages, found both in children at the beginning phases of acquiring serial complexity, and retained in mature speakers across languages.

\section{2}

\section{Ambient language effects}

Limited research, mostly during the first 50 words, suggests some effects of the ambient language during the first-word period. Pye, Ingram, and List (1987) studied Quichualearning children 18 to 36 months of age in Mexico. They found that consonants /ts/ and /1/ were produced frequently, mirroring the greater frequency of these phonemes in Quichua. English-learning children, in contrast, do not frequently produce these phonemes at comparable ages. Ingram (1988), in diary studies based on parent 
transcription, analyzed appearance of $/ \mathrm{v} /$ in first words of single children in Swedish, Estonian, and Bulgarian language environments. / $/$ is a frequent phoneme in Swedish, Estonian, and Bulgarian. These children showed early appearance of $/ \mathrm{v} /$; an English child analyzed for comparison did not. Ingram's data collection method which relied on parent transcribers (who may not be sophisticated in noting sound qualities), as well as the use of a case study method with a small database, suggests caution in interpretation. However, his findings indicate potential ambient language differences by the end of the second year of life.

Gildersleeve-Neumann and Davis (1998) studied first words and concurrent babbling in seven children betweeen 9 and 22 months learning Quichua, an indigenous language spoken in Equador. Quichua child data was compared with characteristic patterns reported for English-learning children. Quichua phonology shows a higher proportion of fricative, affricate and nasal manner and fewer stops and liquids and than English as well as an ejective stop series not found in English. There is also higher use of palatal and dorsal place of articulation and fewer coronals in Quichua than in English.

Stop, nasal and glide manner and coronal place frequencies did not differ between the Quichua and English children. These manner and place categories have been reported as high in frequency during acquisition across languages (Locke, 1983). The consistency in relative frequencies has been interpreted as illustrating production system effects rather than ambient language influences. However, consistent with Quichua ambient language characteristics, the Quichua infants produced higher frequencies of fricatives and affricates and lower liquid and labial frequencies than reports for English-learning infants. The higher frequencies of fricatives and affricates are not consistent with English acquisition data (Gildersleeve-Neumann et al., 2000), indicating potential contribution of ambient language effects in the Quichua child repertoire. Gildersleeve-Neumann and Davis (1998) interpreted their results as supportive of the primacy of production factors, indicated by consistencies in production repertoires between the English and Quichua-learning children. Differences in place and manner patterns in the Quichua infants from those reported for acquisition generally were attributed to Quichua ambient language effects.

Boysson-Bardies and Vihman (1991) studied babbling and first words of five children from four language environments (French, English, Swedish, and Japanese) up to the 25 -word point (defined as the point at which the child produced 25 words during a data collection session). Children in all four groups were highly similar in use of labials, dentals and stops, consistent with the Gildersleeve-Neumann and Davis (1998) results. Boysson-Bardies and Vihman found that Swedish children produced fewer labials and more dorsals than the other groups, consistent with Swedish ambient language characteristics. However, the authors used the targets for the words the children attempted rather than overall ambient language frequencies in their analysis. Clear evidence of ambient language effects is hard to assess, as child lexical target characteristics may not consistently match ambient language phonology. 


\section{3}

\section{Characteristics of Brazilian-Portuguese and English}

To assess potential ambient language influences, characteristics of the languages compared must be outlined. American English and BP show differences which allow evaluation of the relative role of production factors and ambient language influences in acquisition.

In these comparisons frequency characteristics of adult American English used for comparison are based on English frequency surveys in Kent (1994). For BP, a dictionary database (Ferreira, 1977) and an oral language database (Castilho \& Pretti, 1986) were used to generate language frequencies. Phonetic transcriptions of both types of data were used to provide as comprehensive a referent as possible for ambient language characteristics for BP. The BP databases are part of a segment frequency study in two representative corpora (Albano, Moreira, Aquino, Silva, \& Kakinohana, 1995). The dictionary sample consists of orthographic entries $(27,074)$ of the abridged version of one of the most frequently used dictionaries in Brazil (Ferreira, 1977). The spoken language database consists of transcribed samples from 57 tapes. These tapes are from a public database originally collected for a nationwide oral language survey (Castilho $\&$ Pretti, 1986). Data were collected from "a representative number of highly educated adults from five major Brazilian state capitals in various lectures and conversation settings" (p. 346).

In BP, polysyllable word types and CV syllable types are most frequent. In contrast, monosyllables are the most frequent word type in English, and CVC forms are the most frequent syllable type. In both BP and English, coronal consonant place of articulation is most frequent, followed by labial place. For manner, in BP oral plosives are most frequent, fricatives and liquids have almost equivalent frequencies of occurrence and outnumber nasals. English shows a predominance of stop and nasal plosive manner of articulation with fricative and liquid frequencies being much lower. In BP, the fricative element $/ \mathrm{J} /$ which occurs in syllable final position represents the neutralization of the opposition among the initial syllable contrasting fricatives [s], [z], [J], and [3]. The lateral final element $/ \mathrm{L} /$ represents the neutralization of the opposition between syllable initial / / and / w/. The final nonlateral liquid element $/ \mathrm{R} /$ represents the neutralization of the opposition between syllable initial $/ \mathrm{r} /$ and $/ \mathrm{r} /$. In BP, the nasal is not realized phonetically as a segment, but as a strong nasalizing effect (and in some cases also as a diphthongization) on the preceding vowel. In English, only the [h], [j], and [w] phonemes are prohibited in final position, allowing much more diversity in this word position than in BP.

An overview of the BP consonant system is shown in Table 1. In addition, Tables 4 and 5 give specific frequencies of occurrence for place and manner characteristics in BP and English for comparison with results in this study.

Table 2 gives an overview of the BP vowel phonemic system. The English phonemic inventory of vowels includes 13 phonemes, while BP contains 7. See Table 10 for specific frequencies for BP and English vowel types. In the front-back dimension, both the BP and the English data show front vowels in highest frequency although there are substantial differences in frequency between the two BP databases. In the height dimension, midvowels predominate in both the oral and dictionary BP language data. No frequency data are available for height in English. 
TABLE 1

BP consonant phonemes

\begin{tabular}{|c|c|c|c|}
\hline \multicolumn{3}{|c|}{ Syllable Initial Position } & \multirow{2}{*}{ Syllable Final Position } \\
\hline p b & $t d$ & k g & \\
\hline $\mathbf{f} \mathbf{v}$ & $\mathbf{s} \mathbf{z} \quad \int 3$ & & $1 \mathrm{~S} /$ \\
\hline \multirow[t]{5}{*}{$\mathbf{m}$} & $\mathbf{n}$ & & $/ \mathrm{N} /$ \\
\hline & 1 & & $/ \mathrm{L} /$ \\
\hline & 1 & $\mathbf{r}^{*}$ & $/ \mathrm{R} /$ \\
\hline & (j) & (w) & (j) \\
\hline & & & (w) \\
\hline
\end{tabular}

*In most BP dialects realized as a dorsal fricative

\section{TABLE 2}

$\mathrm{BP}$ vowel phonemes

(STRESSED POSITION)

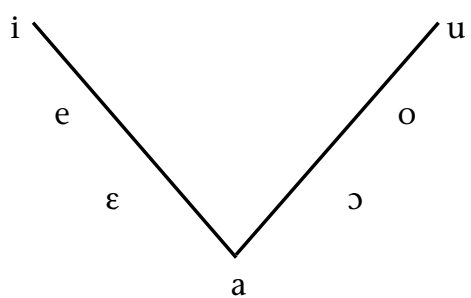

Some information is available on early acquisition in BP. Teixeira $(1980,1985)$ conducted the first systematic studies on the acquisition of the BP sound system. Teixeira (1991) proposed the first analysis of the ordering of BP sounds acquisition, based on a cross-sectional normative study with 216 children in the City of Salvador, Bahia, from ages $2 ; 0$ to $8 ; 0$, sectioned by age groups (in six-month intervals from 2;0 to $5 ; 0$, and one year intervals from 5;0 to 8;0), The PDFP_Perfil do Desenvolvimento Fonológico em Português (A Tentative Set of Developmental Norms in BP, Teixeira, 1991) consists of a set of maturational norms that reflect order of acquisition of sound classes in BP by these typically developing BP children.

In general, Teixiera's results indicate that oral and nasal stops precede semivocalic glides, which precede fricatives and laterals. Labials precede coronals and dorsals, which precede palatals. CV patterns precede CVC; both simple syllable types precede CCV. Several other data bases related to BP acquisition converge on the order of acquisition of BP and confirm the work of Teixeira (e.g., Hernandorena, 1988, 1994, 1999; Lamprecht, 1986, 1990, 1999; Yavas, 1985). Another database is under construction, the INIFONO (Lamprecht, 1999), which will include longitudinal data from four normal infants and cross-sectional data of 96 normally developing children from the ages of $1 ; 0$ to $2 ; 0$ to document earliest stages of acquisition of BP. 
Understanding acquisition of speech production skill requires exploration of both production and perception influences on child learners in various language environments. Acquisition has been more fully explored for English-learning children. Relatively little research is available validating the generality of these characteristics across languages. As a consequence, little information is available to understand the generality of production effects based on studies of English or to evaluate potential perceptual factors represented by ambient language influences. Both confirmation of the generality of production effects and the role of ambient language influences will help to complete a picture of early speech acquisition during this period.

\section{Method}

In this study, two children learning BP were followed from acquisition of first words through 36 months of age. Phonetic characteristics of their consonant and vowel repertoire as well as inter- and intra-syllabic characteristics were analyzed for the period. This was a diary study made by a linguist parent. As is the case for other diary studies of this period made by linguist parents (e.g., Labov \& Labov; 1978; Leopold, 1947; Menn, 1983), audio-records are not consistently available for assessing accuracy/reliability for phonetic transcriptions. As such, these data can contribute to our general knowledge of acquisition of BP and provide a basis of comparison for future studies of acquisition of the language with larger groups of children and more rigorous recording methods allowing reliability assessments of transcribed data.

\section{1}

\section{Participants}

The database in this study was collected longitudinally from two typically developing children between the ages of 12 and 36 months. Both children were raised in a monolingual BP environment and are daughters of the first author. Child 1 (C1), the oldest sibling, was a relatively early talker; her first "real" word (judged as use of a recurrent sound sequence used intentionally in an interactional context) emerged at 11 months. By 16 months, her vocabulary consisted of 50 word types, $25 \%$ of which were part of two-word utterances. In Child 2 (C2), first words emerged at 12 months (after she had been walking for 4 months). At 18 months she had 23 words, $7 \%$ of which were part of two-word utterances.

\section{2 \\ Data}

Data were collected as they occurred in normal daily activities either as novel or recurrent utterance events. They were observed and recorded in a diary format by the children's parent, an experienced phonetic transcriber. Similar to Labov and Labov's (1978) study, phonetic forms were transcribed using IPA notation. Whenever possible, tokens were audiorecorded for further verification.

All word-based data transcribed during the whole period for the two children were analyzed. Criteria for word designation included a referent clearly apparent to the transcriber, based on the communicative context of use. Place and manner for consonants, and height and front-back dimensions for vowels described phonetic characteristics of 
consonants and vowels. Positional occurrence frequencies for consonants were noted related to syllable onset and offset status. Frequency of syllable types was also described. Finally, both intrasyllabic and intersyllabic characteristics of all words were analyzed.

Three types of data were used for comparison with these BP children's data. Words Children Use on the Words and Sentences portion of the MacArthur Communicative Development Inventory (CDI; Fenson et al., 1992) was adapted for BP (Teixeira, 1997). The $C D I$ is a parent report instrument for lexical acquisition normed on English children as well as children in a number of other language communities. The lexical items on the BP-adapted CDI were phonetically transcribed to allow comparison of phonetic characteristics of word targets attempted by BP children with these two children's data.

Since there is no normative database for earliest speech acquisition available in BP, the BP-adapted CDI was completed to assess potential influences of the ambient language. For the BP-adapted CDI, the criterion used for converting lexical items into phonetic transcription was the standard BP phonetic transcription (Cagliari, 1981; Head, 1964; Teixeira, 1985). The English lexical items in the CDI were used as the main reference for word selection. The Spanish CDI (Jackson-Maldonado, Thal, Marchman, Bates, \& Guitierrez-Clellen, in press) was also used, based on the grammatical similarity between Spanish and BP. Some items were deleted for cultural reasons (i.e., lexical items that were not thought to occur in the speech of young BP-speaking children), or due to morphological characteristics of BP (i.e., diminutive forms equivalent to some distinct lexical items in English). The criteria used for the adaptation were also influenced by the results of previously designed articulation instruments for assessing phonological development in BP. (Teixeira, 1980, 1984, 1985, Teixeira, Dourado, Silva, \& Queiroz, 1991). Familiarity of vocabulary to the young Brazilian child was a primary consideration.

A BP dictionary database (Ferreira, 1977) and an oral language database (Castilho $\&$ Pretti, 1986) were used for comparison with ambient language frequencies.

\section{Results}

\section{1}

\section{Overall characteristics}

Analysis was based on a phonetically transcribed corpus of 1,539 utterances, comprising two periods: $0 ; 12$ to $0 ; 23$ (equivalent to the first-word and early two-word periods) and $0 ; 24-0 ; 36$ (as the sound system expanded in complexity). Table 3 displays the total number of types and tokens for each of the two children in the entire corpus. Types and tokens are reported here to underscore the difference in volubility in these two children.

\section{TABLE 3}

Total number of types and tokens for each child in the entire corpus

\begin{tabular}{ccc}
\hline Child & Types & Tokens \\
\hline C1 & 899 & 1031 \\
C2 & 463 & 508 \\
\hline Total & 1362 & 1539 \\
\hline
\end{tabular}


Table 4 displays the frequency of segment, syllable and utterance types for the overall corpus. 5,990 segments were analyzed for the two children across both stages. 2,977 vowels and 3,013 consonants were analyzed. The difference between the children for consonant and vowel totals was less than $1 \%$. Balance of consonant and vowel frequencies reflects a balance between open and close phases, low frequency of consonant clusters, and predominant use of open syllables. Number of syllables closely matches the number of vowels; the difference between the two was less than $1 \%$.

Disyllables were the most frequently occurring word pattern $(51 \%)$, followed by monosyllables (29\%) and polysyllables. The polysyllable category included trisyllables $(18 \%)$ and words of four or more syllables $(2 \%)$.

\section{TABLE 4}

Frequency of occurrence of segments, syllables, and utterance types in the entire corpus

\begin{tabular}{ccccccccc}
\hline & \multicolumn{2}{c}{ Segments } & \multicolumn{2}{c}{ Utterance freq. } & \multicolumn{4}{c}{ Word length } \\
\cline { 2 - 9 } Child & Type & Total & Utts. & $\begin{array}{l}\text { Total } \\
\text { sylls. }\end{array}$ & $\begin{array}{c}\text { Mono- Disyl. } \\
\text { sylls. }\end{array}$ & Trisyl. & 4 Syl. \\
\hline C1 & C & 2009 & 1031 & 2002 & 311 & 527 & 166 & 27 \\
& V & 1992 & & & & & & \\
C2 & C & 1004 & 508 & 985 & 134 & 239 & 117 & 18 \\
& V & 985 & & & & & & \\
\hline Total & & 5990 & 1539 & 2987 & 445 & 566 & 283 & 45 \\
\hline
\end{tabular}

\section{2}

\section{Consonant place and manner characteristics}

Consonant place of articulation results are displayed in Table 5 for both periods and overall. For the children's data, coronal and palatal fequencies are listed together. The BP-adapted CDI, oral and dictionary BP and English language frequencies are listed also.

Overall, coronal was the most strongly represented place $(52 \%)$, followed by labial $(27 \%)$. The least frequently occurring consonant place was dorsal. These trends seem to be quite stable throughout the two age periods studied for both these children.

In all four comparison databases, coronals are highest in frequency. For all three of the BP databases, dorsals are higher in frequency than in the English data $(23 \%, 16 \%$ and $15 \%$ compared to $9 \%$ for English). The BP-adapted CDI, data also shows a $23 \%$ frequency for dorsals which is very close to the frequency for the two children $(21 \%)$. This higher use of dorsals is similar to the ambient language but not consistent with frequencies reported across languages as well as in English for the first word period (e.g., Davis \& MacNeilage, 1990; Locke, 1983; Stoel-Gammon, 1985).

In addition, both the BP-adapted CDI and these children's data show a higher frequency of labials compared to the percentages for BP and English. This increase in 
use of labials in first words compared to their frequency in babbling has been noted for a variety of languages (e.g., Boysson-Bardies, Vihman, Roug-Hellichius, Durand, Landburg, \& Arao, 1992; Davis et al., 2002; Stoel-Gammon, 1985).

\section{TABLE 5}

Consonant place of articulation: percentage of occurrence for both children across stages and I BP target consonant inventories compared to English

\begin{tabular}{lccccccc}
\hline & $\begin{array}{c}\text { Period (1) } \\
0 ; 12-0 ; 23\end{array}$ & $\begin{array}{c}\text { Period (2) } \\
0 ; 24-0 ; 36\end{array}$ & $\begin{array}{c}\text { Overall } \\
0 ; 12-0 ; 36\end{array}$ & BP-CDI & Oral BP & $\begin{array}{c}\text { Dictionary } \\
\text { BP }\end{array}$ & English \\
\cline { 2 - 8 } Labial & 28 & 26 & 27 & 23 & 19 & 20 & 22 \\
Alv./Pal. & 50 & 53 & 48 & 54 & 65 & 65 & 67 \\
Dorsal & 22 & 21 & 21 & 23 & 16 & 15 & 9 \\
\hline
\end{tabular}

Table 6 displays consonant manner percentages for the two children for each stage and overall percentages for the entire period of the study. In addition, comparison data on the BP-adapted CDI, the oral and dictionary BP and English are shown. For the two BP children, oral plosives represent $46 \%$ of all consonant occurrences in the entire corpus. Fricatives $(16 \%)$, nasal plosives $(14 \%)$ and glides $(13 \%)$ are also relatively frequent. Liquids occurred least often overall. The split-half analysis shows some developmental trends. In the first period, oral and nasal plosives and glides are highest in frequency for the BP children, as has been reported for English-learning children. In the second period, the order of frequency is strongly related to the BP databases except for the use of more nasals than fricatives, although there is a significant increase $(14 \%)$ in the number of fricatives from the first to the second period for the children.

\section{TABLE 6}

Percentage of manner of articulation for both children across stages and in BP target consonant inventories compared to English

\begin{tabular}{lccccccc}
\hline $\begin{array}{l}\text { Consonant } \\
\text { Manner }\end{array}$ & $\begin{array}{c}\text { Period (1) } \\
0 ; 12-0 ; 23\end{array}$ & $\begin{array}{c}\text { Period (2) } \\
0 ; 24-0 ; 36\end{array}$ & $\begin{array}{c}\text { Overall } \\
0 ; 12-0 ; 36\end{array}$ & BP CDI & Oral BP & Dict. BP & English \\
\hline Plosives & 50 & 42 & 46 & 41 & 37 & 39 & 32 \\
Fricatives & 9 & 23 & 16 & 20 & 25 & 23 & 26 \\
Nasals & 14 & 13 & 14 & 10 & 12 & 9 & 18 \\
Liquids & 12 & 12 & 11 & 23 & 18 & 24 & 13 \\
Glides & 15 & 10 & 13 & 6 & 8 & 5 & 7 \\
\hline
\end{tabular}

\section{3}

\section{Consonant positional effects}

Consonant frequencies in syllable onset position are shown in Table 7 for $\mathrm{C} 1$ and $\mathrm{C} 2$ individually and for both children in the first and second stages and overall. In syllable onset, 2,631 consonants were recorded for both children across stages. The number of 
consonants was 1,370 in the first period and 1,261 in the second for both children. Thirteen consonant phones occurred at frequencies less than $5 \%$; fricatives ([f, v, $\mathrm{z}, \mathrm{S}$, $\mathrm{Z}]$ ), palatals $[\mathrm{I}, \mathrm{r}, \mathrm{j}])$, dorsals $([\mathrm{r}, \mathrm{w}, \mathrm{g}])$, the $[\mathrm{r}]$ and $[\mathrm{n}]$.

Places represented most frequently were coronal and dorsal, but not in the same order for BP adults and BP children. The adult BP oral $[\mathrm{t}, \mathrm{d}, \mathrm{k}]$, and dictionary: $[\mathrm{t}, \mathrm{d}$, $\mathrm{k}$ ] data showed a reversal of the dorsal-coronal ranking found for the two children. It should be noted that the top three place frequencies in all instances represented only $10-12 \%$ of occurrences overall. For both the child and adult data, many sound types were utilized, albeit at very low frequency of occurrence.

For the children, the most frequently produced consonant phone was [k] $(12.5 \%)$. This trend was observed for $\mathrm{C} 1$ in both stages. For C2, [k] was not frequent in the first stage but was the second most occurring single segment in the second stage. The frequency of the dorsal and coronal voiceless plosives in $\mathrm{C} 2$ is consistent with the frequency of occurrence in the comparison databases for BP. In the BP-adapted CDI, the phoneme $[\mathrm{k}]$ is also the most frequent syllable onset consonant. The relative frequency for dorsal place is higher than noted for English (see Table 3).

The other most frequent single phone in syllable-onset position for both children was [p] $(10.3 \%$ overall). When grouped with [b], the total frequency for labial plosives was $18.6 \%$. For both children, relative frequency of [p] and [b] declined during the second period. The first period in this study compares to the first word period in other studies, where increase in use of labials has been noted (Boysson-Bardies \& Vihman, 1991; Davis et al., 2002). In both English and BP, coronals are the most frequent consonant place, as has been noted across languages (Paradis \& Prunet, 1991).

Table 8 shows frequencies of consonants in syllable-offset position for both children for each period and overall, percentages of occurrence for the BP-adapted CDI and the two BP databases. The phones occurring in syllable final position for the children are similar to BP, although a few other phones occur with very low frequency. The most frequently occurring phone for the children is a nasal (35\%). They show far higher use of glides $/ \mathrm{w} /$ and $/ \mathrm{j} /$ than either BP or the BP-adapted CDI data. In contrast, their use of both liquids and fricatives is much lower than in either the BP-adapted CDI or the BP data. This occurrence of fricatives and liquids is consistent with reported low frequency of occurrence for these phone types in children at this stage across languages (Locke, 1983). Results of the split-half analysis showed an overall increase of $5 \%$ in terms of the frequency of use of offset phones from the first period to the second. 


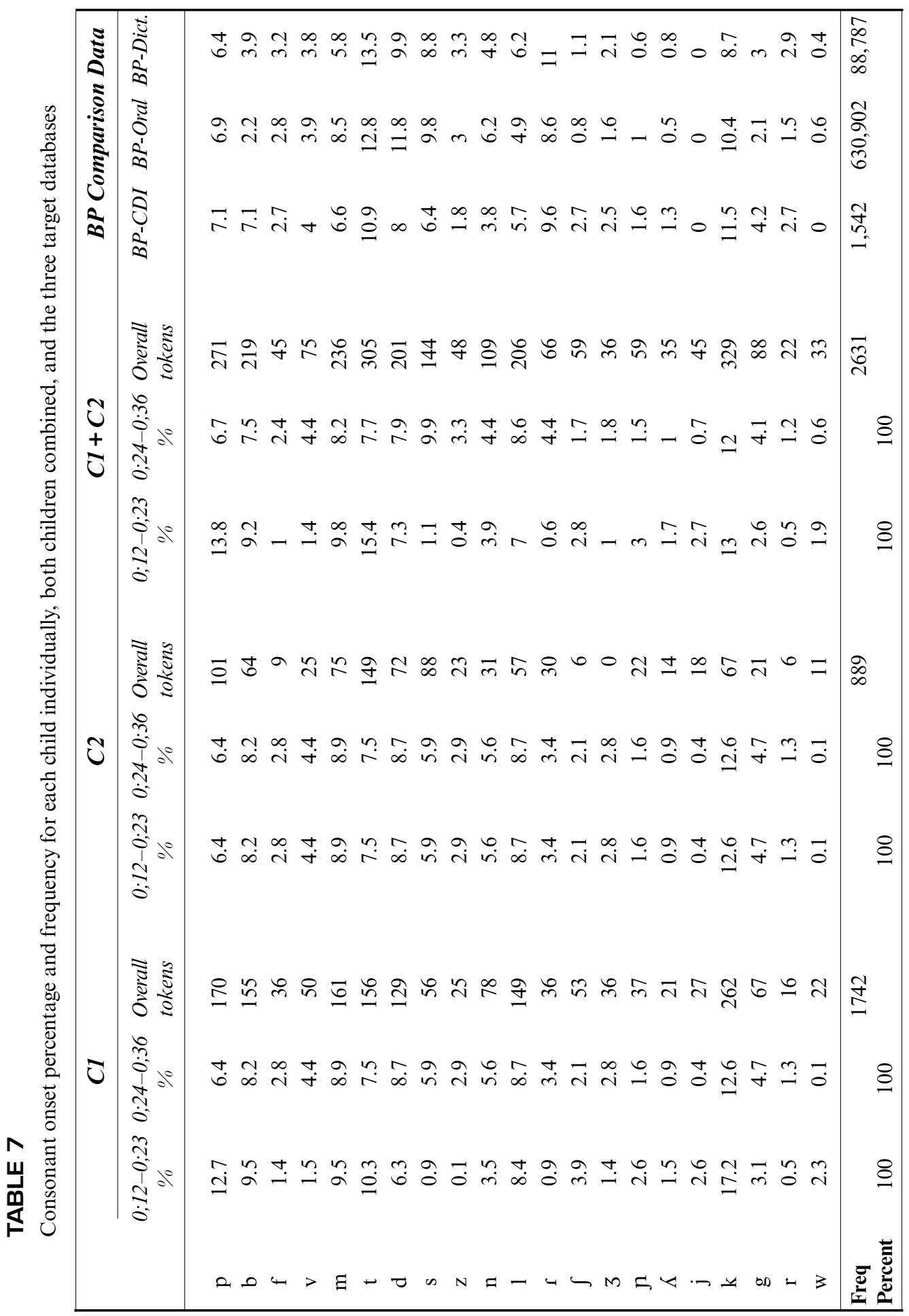




\section{TABLE 8}

Percentage of occurrence of segments in Syllable Final Position for each stage for the entire corpus and in the three target databases

\begin{tabular}{|c|c|c|c|c|c|c|c|}
\hline Element & $\begin{array}{c}* \text { Word } \\
\text { position }\end{array}$ & $\begin{array}{l}\text { Period } \\
\text { (1) }\end{array}$ & $\begin{array}{l}\text { Period } \\
\text { (2) }\end{array}$ & Total & $B P C D I$ & Oral BP & Dict. $B P$ \\
\hline & Ww & 19 & 62 & & & & \\
\hline \multirow[t]{2}{*}{ /N/ } & Wf & 65 & 60 & 35 & 38 & 38 & 40 \\
\hline & Ww & 2 & 17 & & & & \\
\hline \multirow[t]{2}{*}{$/ \mathrm{S} /$} & Wf & 5 & 13 & 6 & 14 & 23 & 18 \\
\hline & Ww & 3 & 14 & & & & \\
\hline \multirow[t]{2}{*}{$/ \mathrm{R} /$} & Wf & 0 & 1 & 3 & 19 & 12 & 16 \\
\hline & Ww & 2 & 5 & & & & \\
\hline \multirow[t]{2}{*}{ /L/ } & Wf & 4 & 5 & 3 & 6 & 4 & 9 \\
\hline & Ww & 9 & 1 & & & & \\
\hline \multirow[t]{2}{*}{ /y/ } & Wf & 93 & 57 & 27 & 1 & 9 & 7 \\
\hline & Ww & 2 & 4 & & & & \\
\hline /w/ & Wf & 75 & 70 & 26 & 10 & 14 & 10 \\
\hline
\end{tabular}

$* \mathrm{Ww}=$ within word; $\mathrm{Wf}=$ word finally

\section{4}

\section{Vowels}

Table 9 shows vowel types used by the children. All BP vowel types occurred. The midback vowels $/ \mathrm{J} /$ and /o/ were lowest in frequency. Only /a/ was produced with a higher frequency than $35 \%$ in both children. The high front and high back vowels $/ \mathrm{i} /(19 \%)$ and $/ \mathrm{u} /(14 \%)$ were the next most frequently occurring vowels for both children.

\section{TABLE 9}

Percentage of vowel occurrence for each period and in the entire corpus

\begin{tabular}{cccc}
\hline Vowel type & $\begin{array}{c}\text { Period (1) } \\
\text { (percent) }\end{array}$ & $\begin{array}{c}\text { Period (2) } \\
\text { (percent) }\end{array}$ & $\begin{array}{c}\text { Average } \\
\text { (percent) }\end{array}$ \\
\hline /i / & 17 & 20 & 18.5 \\
/e/ & 8 & 13 & 10.5 \\
/ $/$ / & 5 & 6 & 5.5 \\
/u/ & 13 & 14 & 13.5 \\
/o/ & 6 & 6 & 6 \\
/J/ & 5 & 3 & 4 \\
/a/* & 46 & 38 & 42 \\
\hline
\end{tabular}

*The vowel [ $\mathrm{t}$ ] was grouped with [a], as they occur in complementary distribution in the language. The realization [«], which is sometimes found as a free variant of [t], was also grouped with the low central vowel. 
Table 10 shows results of analysis for vowel types in the front-back and height dimensions. Overall, in the front-back dimension, central vowels were the most dominant category for both children across stages $(42 \%)$, followed by front vowels $(35 \%)$ and back vowels (23\%). Results of the split-half analysis showed central and front vowels occurring at almost the same rate (38\% and 39\%, respectively) in the first age period studied $(0 ; 12-0 ; 23)$, consistent with patterns reported for English-learning children. In the height dimension, low vowels predominated (45\%), again consistent with patterns reported for English-learning children. In the second period, use of front vowels increased and the distribution of vowels across the height dimension was more equal, moving toward ambient language characteristics for BP.

\section{TABLE 10}

Percentage of vowel height and front-back occurrences for each stage and in the entire corpus and percentage of vowels in BP-CDI, Oral, and Dictionary BP and English

\begin{tabular}{lcccccc}
\hline & \multicolumn{3}{c}{ Vowel front-back } & \multicolumn{3}{c}{ Vowel height } \\
\cline { 2 - 7 } & Front & Central & Back & High & Mid & Low \\
\hline Period 1 & 39 & 38 & 23 & 30 & 24 & 45 \\
Period 2 & 45 & 30 & 24 & 35 & 28 & 38 \\
Average & 42 & 34 & 23 & 32 & 26 & 42 \\
BP CDI & 35 & 36 & 29 & 40 & 25 & 35 \\
Oral BP & 43 & 31 & 26 & 8 & 61 & 31 \\
Dict. BP & 40 & 34 & 26 & 23 & 43 & 34 \\
English & 44 & 40 & 20 & & & \\
\hline
\end{tabular}

Table 10 also displays comparison data for the BP-adapted CDI, for the dictionary and oral BP and for English. English-learning children as well as these two BP children and the BP-adapted CDI show the same higher frequency of front and central vowels. Thus, the front $\rightarrow$ central $\rightarrow$ back distribution of frequency is consistent for this child data. Data in both English and BP show predominance of front vowels.

English height frequencies are not available for comparison with BP. In addition, the comparison in terms of height is not so straightforward due to the method used for converting the two BP adult databases into phonological transcription. "For morphological coherence, orthographic e and o are always assigned to /e/ and /o/, though phonetic $[\mathrm{i}]$ and $[\mathrm{u}]$ tend to surface in most poststressed and prestressed contexts." (Albano et al., 1995, p. 347). Two important facts should be noted in describing vowel height in these children: the predominance of low vowels and the relatively lower occurrence of mid vowels $(26 \%)$ than high vowels (32\%) from the earliest age period studied. These results also support findings of a previous large-scale cross-sectional study with Brazilian children from age 2;0 to 8;0 years (Teixeira, 1991). Comparing these results with BP-adapted CDI and BP language results shows a predominance of high vowels in the BP-adapted CDI as well. Mid vowels predominated in the BP oral and dictionary language data. 
In summary, these BP children show the predominance of front and central vowels reported in other studies of this period. In the height dimension, differences are in higher frequencies of high vowels than have been reported elsewhere. This effect may be due to the increased use of diminutives in early child forms in BP, as it also occurs in the BP-adapted CDI. These diminutives typically contain the high vowels [i] or [I].

\section{5}

\section{Syllable types}

Percentage of occurrence of syllable types for both children in both periods is shown in Table 11. The preferred syllable type across stages for both children was an open syllable with onset CV (72\%). Eleven percent of the syllables have no onset and only $12 \%$ have offset (most of which are occupied by glides (71\%)). The frequencies for these children are very close to those in the BP-adapted CDI. In addition, these relative frequencies reflect phonotactic tendencies of $\mathrm{BP}$, as can be seen by the results of the syllable type occurrence in the dictionary database on the right column (Teixeira \& Silva, 1999). There are no frequency count studies on syllable types available for the oral BP database. Complex onsets do not occur frequently (4\%), consisting in many cases $(32 \%$ in the first period) of obstruents + glides. In English, CVC is the most frequent syllable type (Kent, 1994). Complex onsets account for only $3.6 \%$ of onsets; complex offsets for $13 \%$ of offsets overall.

\section{TABLE 11}

Percentage of occurrence of syllable types for both stages, in the CDI Database and the Dictionary Database

\begin{tabular}{lccccc}
\hline Syllable Type & Period (1) & Period (2) & Average & $\begin{array}{c}\text { CDI } \\
\text { database }\end{array}$ & $\begin{array}{c}\text { Dictionary } \\
\text { database }\end{array}$ \\
\hline & \multicolumn{5}{c}{ (percent) } \\
V & 11 & 12 & 12 & 9 & 7 \\
CV & 75 & 69 & 72 & 63 & 56 \\
(C) (C) VC & 12 & 12 & 12 & 23 & 27 \\
CCV (C) & 2 & 6 & 4 & 5 & 8 \\
(C) (C) VCC & 0 & 0 & 0 & 0 & 2 \\
\hline
\end{tabular}

\section{6}

\section{Intrasyllabic patterns}

There are no available studies of intrasyllabic and intersyllabic patterns for the two BP databases so only the BP-adapted CDI database is shown in Tables 12 and 13. Table 12 displays intrasyllabic CV co-occurrence results for labials, coronals, and dorsals in front, central and back vowel environments for each period and for the BP-adapted CDI. This analysis tests the prediction that intrasyllabic CV patterns of labial-central, coronalfront, and dorsal-back consonants are reflective of lack of independent movement of articulators relative to the jaw within syllables. For the labial case, no tongue movement 
is involved in the labial closure, so a central vowel results; for the coronal and dorsal cases, the open phase for the vowel is in the same place as the closure place for the consonant (i.e., front and back respectively). In Table 12, the total number of syllables analyzed is listed in the far right column. Results are expressed as a ratio of observed to expected frequencies in each cell (expected value is 1.0). Expected frequencies for each of the three vowel categories were calculated from the overall frequency of that vowel and that consonant in the corpus. Thus, if $40 \%$ of all vowels in the corpus were central vowels, then $40 \%$ of all vowels in each consonant environment would be expected to be central vowels. The predicted associations are in bold along the diagonal. $\mathrm{C} 1$ showed all three predicted CV associations. Only dorsal-central vowel associations were above expected in the nonpredicted cells for $\mathrm{C} 1$. For $\mathrm{C} 2$, only the dorsal-back vowel cooccurrence showed above expected association. In addition, nonpredicted labial-front vowel and coronal-back vowel associations were present. The BP-adapted CDI results showed predicted labial-central and dorsal-back vowel associations. Nonpredicted labial-front vowel and coronal-back vowel associations were found in the CDI.

\section{TABLE 12}

Percentage of CV co-occurrence relations for both children across stages and in the BPadapted CDI

\begin{tabular}{|c|c|c|c|c|c|}
\hline \multirow{2}{*}{ Child Iperiod } & \multirow{2}{*}{ Vowel place } & \multicolumn{4}{|c|}{ Consonant place } \\
\hline & & Coronal & Labial & Dorsal & Total \\
\hline \multirow[t]{3}{*}{ C1 Early } & Front & 1.08 & 0.94 & 0.97 & 294 \\
\hline & Central & 0.83 & 1.32 & 0.84 & 437 \\
\hline & Back & 1.23 & 0.46 & 1.31 & 239 \\
\hline \multirow[t]{3}{*}{ C1 Late } & Front & 1.08 & 0.93 & 0.85 & 288 \\
\hline & Central & 0.95 & 1.27 & 0.93 & 283 \\
\hline & Back & 0.94 & 0.91 & 1.32 & 183 \\
\hline \multirow[t]{3}{*}{ C2 Early } & Front & 0.98 & 1.11 & 0.39 & 97 \\
\hline & Central & 0.98 & 1.03 & 0.91 & 167 \\
\hline & Back & 1.08 & 0.72 & 2.16 & 62 \\
\hline \multirow[t]{4}{*}{ C2 Late } & Front & 0.92 & 1.41 & 0.66 & 173 \\
\hline & Central & 1.05 & 0.67 & 1.27 & 192 \\
\hline & Back & 1.02 & 0.90 & 1.04 & 109 \\
\hline & & \multicolumn{4}{|c|}{ Comparison data } \\
\hline \multirow[t]{3}{*}{ BP-CDI } & Front & 0.91 & 1.23 & 0.86 & 372 \\
\hline & Central & 0.97 & 1.04 & 0.99 & 734 \\
\hline & Back & 1.2 & 0.55 & 1.22 & 265 \\
\hline
\end{tabular}

\section{7}

\section{Intersyllabic patterns}

Table 13 displays data on intersyllabic patterns of reduplication and variegation for the children for each period. Both reduplicated and variegated patterns coexisted across the 
whole period. In the first period, reduplicated patterns $(53.6 \%)$ outnumbered variegated. In the second, there were far fewer reduplicated sequences (37.3\%). Overall, the frequency of variegated patterns $(54.4 \%)$ was somewhat higher than reduplicated $(45.6 \%)$.

Reduplication of the place feature coronal $(C+C, 30.8 \%)$ was the most frequent pattern of association between consonants in two consecutive syllables the onset of two consecutive syllables both in each of the age periods and overall. The variegated patterns $\mathrm{L}+\mathrm{C}(20.7 \%), \mathrm{D}+\mathrm{C}(13.3 \%)$ and the reduplicated pattern $\mathrm{L}+\mathrm{L}(11.3 \%)$ ranked next in overall frequency. $\mathrm{C} 1$ 's use of variegated $\mathrm{D}+\mathrm{C}$ and reduplicated $\mathrm{D}+\mathrm{D}$ is far more frequent than $\mathrm{C} 2$ in the first period. In the second period, the difference between the two children decreased.

The most common variegated pattern was $\mathrm{L}+\mathrm{C}(21 \%)$. It was by far the most frequent pattern in the data for these BP children. This pattern has also been noted for 9 of 10 English-learning children as well as in disyllables in 9 of 10 languages (MacNeilage, Davis, Kinney, \& Matyear, 2000a). Table 13 also shows the analysis for the BP-adapted CDI for comparison with the results from the BP children. C+C $(26 \%)$ is the most frequent reduplicated form and $\mathrm{L}+\mathrm{C}(25 \%)$ is the most frequent variegated form, consistent with results for these children, indicating that the phonetic characteristics of their productions are much like the phonetic characteristics of words frequently attempted by BP-learning children. In both these children and the BP-adapted CDI, the second most frequent variegation is D + C. On the BP-adapted CDI, reduplicated utterances accounted for $34 \%$ of disyllable sequences compared with $45 \%$ in the children's productions.

\section{TABLE 13}

Reduplication/Variegation patterns for both children: (a) From 0;12 to 0;23, (b) From $0 ; 24-0 ; 36$, and (c) In the entire corpus; and in the BP-CDI corpus

\begin{tabular}{|c|c|c|c|c|c|c|c|c|}
\hline \multirow[b]{3}{*}{ Pattern } & \multicolumn{5}{|c|}{ Age period } & & \multirow[b]{3}{*}{$\begin{array}{l}\text { Overall } \\
\text { freq. } \%\end{array}$} & \multirow[b]{3}{*}{$\begin{array}{c}B P \\
-C D I \% \\
\end{array}$} \\
\hline & \multicolumn{3}{|c|}{$0 ; 12-0 ; 23$} & \multicolumn{3}{|c|}{$0 ; 24-0 ; 36$} & & \\
\hline & $C 1 \%$ & $C 2 \%$ & $\begin{array}{l}\text { Sub- } \\
\text { total }\end{array}$ & $\mathrm{Cl}^{\circ} \%$ & $C 2 \%$ & $\begin{array}{l}\text { Sub- } \\
\text { total }\end{array}$ & & \\
\hline $\mathrm{L}+\mathrm{L}$ & 17 & 15.3 & 16.6 & 6.3 & 5.2 & 5.8 & 11.3 & 4 \\
\hline $\mathrm{C}+\mathrm{C}$ & 26.9 & 40.9 & 30.4 & 26.2 & 33.2 & 29.6 & 30 & 26 \\
\hline $\mathrm{D}+\mathrm{D}$ & 8.4 & 1.5 & 6.6 & 1.1 & 2.8 & 1.9 & 4.3 & 3 \\
\hline $\mathrm{L}+\mathrm{C}$ & 17.2 & 22.6 & 18.6 & 21.8 & 24 & 22.8 & 20.7 & 25 \\
\hline $\mathrm{L}+\mathrm{D}$ & 3.4 & 3.6 & 3.5 & 9.6 & 7.2 & 8.4 & 5.9 & 7 \\
\hline$C+D$ & 3.7 & 2.9 & 3.5 & 5.5 & 4.4 & 5 & 4.2 & 5 \\
\hline $\mathrm{C}+\mathrm{L}$ & 3.2 & 11 & 5.2 & 7.4 & 8.4 & 7.9 & 6.5 & 9 \\
\hline $\mathrm{D}+\mathrm{L}$ & 4.7 & 0 & 3.5 & 5.2 & 3.2 & 4.2 & 3.9 & 6 \\
\hline $\mathrm{D}+\mathrm{C}$ & 15.5 & 2.2 & 12.2 & 17 & 11.6 & 14.4 & 13.3 & 14 \\
\hline Raw Total & 406 & 137 & 543 & 271 & 250 & 521 & 1064 & \\
\hline
\end{tabular}




\section{Discussion}

This study sought to investigate the interaction between production factors and perception influences from the ambient language in acquisition of speech production. These issues were addressed by analyzing word-based acquisition data for two Brazilian Portuguese learning children between 12 and 36 months of age. BP data in this corpus was compared with data available for English-learning children as well as with the characteristics of early targets that BP children frequently attempt (BP-adapted CDI) and $\mathrm{BP}$ oral and dictionary based phonological patterns for the target language. This was a study of phonetic patterns rather than a study of production accuracy. The goal was to evaluate phonetic patterns in acquisition of BP, a step to understanding the development of production accuracy and phonological competence.

The major finding of this study was the similarity of production patterns in BP with patterns found in other studies of early speech acquisition. These effects were most apparent in the first period in these children, which coincided with the period of single word and early two word combinations. However, evidence of specific ambient language effects related to BP was noted in both children during both periods.

Both children's productions were characterized primarily by use of labial and coronal stops in simple syllable shapes, as has been noted across languages (e.g., Locke, 1983). Similarity in production patterns across languages suggests the importance of child internal production factors rather than early influences of the ambient language. However, ambient language influences appear even in earliest lexical acquisition in more frequent use of dorsals and of multisyllabic word types in these two BP-learning children. In the general sense, these findings support a hypothesis of dual influences on acquisition, in which the child's early sound patterns are primarily, though not entirely, based on production effects, but may also be subject to perceptual influences from the ambient language. Where present, early effects of the ambient language may potentially challenge notions of child production patterns based on articulatory ease. For example, monosyllables could be seen as "easier" than disyllables or polysyllables for production. In English, monosyllables predominate in early acquisition and in the ambient language. However, in a language such as Spanish or BP in which multisyllables are more frequent, early predominance of multisyllable over monosyllable use would suggest that monsyllable use is not synonymous with simplicity for the production system in acquiring serial complexity.

\section{1}

\section{Consonant place of articulation}

In this study, analysis of consonant place showed that coronal was the most frequent place of articulation in each period and overall, mirroring both BP databases as well as the BP-adapted CDI. The primacy of coronal place of articulation has been noted broadly both in studies of acquisition (Locke, 1983; also see Vihman, 1996 for a review) and in languages (Paradis \& Prunet, 1991). This effect has been interpreted phonetically as a primacy of tongue front articulation in the service of complex message transmission (MacNeilage et al., 2000b), which could suggest characteristics of the production mechanism common in both children and adults rather than obviously indicating 
influence of learning from the ambient environment during acquisition.

Some studies of speech acquisition (Boysson-Bardies \& Vihman, 1991; MacNeilage et.al, 1997; Stoel-Gammon, 1985) have noted an increase in frequency of labials in the first word period relative to their frequency of use in babbling in infants. Higher frequency of labial use in first words relative to babbling frequencies has been interpreted as a production system effect. MacNeilage et al. (1997) have argued that use of the tongue-neutral labial consonants (which do not match English language frequencies) during the first word period in English speaking children is evidence of production in contrast to potential perceptual effects in early words, since coronals are higher in frequency in English. In first words, children must for the first time utilize the phonetic patterns available in babbling to interface the production system with intentional meaning, creating a potential functional load issue for the production system. This difference between infants and language patterns has been noted (e.g., MacNeilage \& Davis, 2000) as potentially related to initiation of utterances in the first word period using a closure that does not require tongue engagement, a "start easy — end hard" principle. In this view, use of labials emerges from a basic close open cycle of mandibular oscillation (Davis et al., 2002) in service of initial attempts to attach sound to meaning. In mature language users, the production system is flexible enough to exploit the variety afforded at the coronal place of articulation for producing a wider spectrum of consonant types to initiate words.

The high frequency of labials in first words was not so strikingly apparent in these BP-learning children during the first period (12-23 months), coinciding with the early word stage. However, labials were higher in frequency in these children throughout the study than in any of the three BP databases. Persistence of labial use at higher frequencies than the ambient language until 36 months rather than only in the first word period, as has been noted in previous studies, should be investigated to explore potential for persistence of a subtle production system effects throughout early acquisition.

The early presence of dorsals in these two BP-learning children, however, may be indicative of early ambient language effects. In all three BP databases, dorsals show a higher frequency of occurrence than in English. Dorsals have also been reported as showing low frequency of occurrence during the first word period in English-learning infants (Locke, 1983; Vihman et al., 1985, 1986; Stoel-Gammon, 1985). Dorsals are produced with the back of the tongue rather than the front. Low frequency of dorsals has been interpreted as related to relative ease of production in use of the tongue front for consonant closure. Their occurrence in early acquisition in higher frequencies in $\mathrm{BP}$, where the ambient language also shows relatively higher frequencies, potentially challenges a production ease hypothesis as the only explanation for their generally reported late occurrence in English acquisition studies.

\section{2}

\section{Consonant manner of articulation}

In the earliest age period studied, the order of frequency of consonant manner types in these children was: plosives $\rightarrow$ glides $\rightarrow$ nasals $\rightarrow$ liquids $\rightarrow$ fricatives, consistent with available studies of early acquisition in English. In the later period $(0 ; 24-0 ; 36)$ the children's order of frequency more closely mirrored the BP ambient environment (plosives-fricatives-liquids-nasals-glides). In contrast, in English-learning children, 
nasals are reported as occurring at much higher frequencies than liquids. Nasals are also more frequent than liquids in English. There was also an increase in the number of fricatives from the first to the second age period in these children, consistent with the order of frequency in BP and with the increase in frequency of fricatives reported for English-learning children in later development. Both these children's data as well as data for English-learning children seem to suggest development toward ambient language frequencies after the first word period, especially for liquids and fricatives. This progression toward features particular to the ambient language is consistent with increasing control over independent movements of articulators within sequences after the first word period.

\section{3}

\section{Positional effects}

Consonant occurrence patterns in syllable onset and offset position were also examined. In both the children's data, and the targets reported for BP children, represented by the BP-adapted CDI, dorsal place predominated over coronal in syllable onset position.

The 13 consonant segments with the lowest occurrence (i.e., less than $5 \%$ of the time $)$ in the children's data were fricatives $\left(\left[\mathrm{f}, \mathrm{v}, \mathrm{z}, \int, 3\right]\right)$, palatals $([\mathrm{I}, \mathrm{r}, \mathrm{j}])$, dorsals $([\mathrm{r}$, $\mathrm{w}, \mathrm{g}])$, and $[\mathrm{n}]$. The limited frequency of occurrence of these phones is consistent with Locke's (1983) survey of acquisition data across languages.

In syllable final position, the types of phones occurring are generally the same as in the BP databases. Most syllable final elements occurred in word final position for these children. The largest difference between the frequency of syllable final elements in the BP children's data and in the BP-adapted CDI forms was these children's more frequent use of the glides, in contrast to the target databases, where [ $\left.\int\right]$ was most frequent. Use of glides with greater frequency than fricatives is reported for English-learning children as well (Stoel-Gammon, 1985).

\section{4}

\section{Vowel patterns}

Overall, central and front vowels were the most frequent phones in both BP children's inventories throughout both periods. This finding is consistent with reports for Englishlearning children (e.g., Kent \& Bauer, 1985) suggesting that early vowel qualities are located in the lower left quadrant of the vowel space. However, in the height dimension, the lower occurrence of mid vowels compared to high vowels in these BP children does not support other findings on early vowel use for English where low and mid vowels are more frequent (Davis et al., 2002). This trend toward more high vowels was observed from the earliest age period studied. The BP-adapted CDI also showed a predominance of high vowels. In addition, these results support findings of a previous large-scale crosssectional study of BP children (Teixeira, 1991), that the BP vowel system seems to be acquired prior to the age of two. In contrast, the BP oral and dictionary data show a predominance of mid over high vowels, due to the transcription methodology used in these studies. Potentially, these differences in frequency between the child and adult databases may indicate effects of inflectional use of diminutives in the child corpora. Use of the high front [i] vowel is common in child-directed speech styles as well as part of the early lexicon. This possibility should be explored in lexical analysis of child forms as well as in analysis of lexical frequency in child-directed speech in BP. 


\section{5}

\section{Word shapes}

Contrary to what has been reported for English (Kent, 1994), most forms in the BP children's data were disyllables, followed by monosyllables and polysyllables. BP has been noted as showing predominance of polysyllables (i.e., words of $3+$ syllables) over monosyllables (Albano, 1993; Câmara, 1972; Teixeira, 1997). These BP children appear to be showing early effects of the ambient language in matching word level complexity. Greater incidence of multisyllabic words and few closed syllables in early word acquisition have been shown in studies of a Romanian 24-month old child (Vogel, 1975), an Italian-American English bilingual two-year old child (Ingram, 1981/2), a French infant (Levitt \& Uttman, 1992), as well as 16 Spanish-learning infants (Oller \& Eilers, 1982). Although these findings cannot be taken as conclusive, results for differing languages in which the ambient language is characterized by greater frequency of polysyllables, suggests that syllable shapes and word length may show the influence of ambient language during the first word stage.

$\mathrm{CV}$ is by far the most frequent syllable shape for these BP children, confirming what has been noted frequently in early acquisition. The limited occurrence of final consonants $(12 \%)$ and consonant clusters in the children's data are also reported in English (e.g., Vihman et. al., 1985, 1986), French (Boysson-Bardies, Sagart, \& Bacri, 1981) and Spanish (Oller \& Eilers, 1982). The BP language also shows few clusters and a limited inventory of final consonants (Cagliari, 1981; Camara, 1972; Head, 1964; Teixeira \& Silva, 1999). Thus, in the area of syllable complexity, these children are following the patterns noted in children across languages.

\section{6}

\section{Intrasyllabic patterns}

The three CV co-occurrence patterns (i.e., labial/central, coronal/front, dorsal/back) have been shown in babbling and first words in English (Davis \& MacNeilage, 1995; Davis et al., 2002). In C1, these CV co-occurrences were present in both the first and second period. C2 did not show all of the predicted $\mathrm{CV}$ co-occurrence patterns. In the first period, she produced predicted labial/central and dorsal/back co-occurrences but coronals were found to co-occur with back vowels. This finding may be related to the unexpectedly high frequency of high back vowels in the children's corpus, although not predicted by the "Frames then Content" hypothesis of MacNeilage and Davis (1990, 1993). In the second period, $\mathrm{C} 2$ showed only the dorsal-back vowel association. However, in the second period, C2 was 24 to 36 months of age, a period of strong lexical expansion. As these data were not recorded systematically, some possibility of lexical bias exists whereby frequency of lexical use may skew phonetic frequencies. There were no comparable results available from the two $\mathrm{BP}$ databases to draw comparisons with the ambient language. More analysis of BP is necessary before definitive comparisons with acquisition data can be confidently established.

\section{7 \\ Intersyllabic patterns}

Reduplicated forms were predominant $(53.5 \%)$ in the first age period. "Consonant harmony" is frequently described in earliest acquisition and seems consistent with these 
children's data. Reduplicated forms decreased to $38 \%$ in the second period, showing more language-like variegation patterns. Overall, the BP-adapted CDI showed 34\% reduplication, more similar to the frequency in the second period for these children.

Several authors (e.g., Ingram, 1974; MacNeilage et al., 2000a) have suggested that the first variegated pattern consists primarily of labial-coronal (L-C) consonant sequences. Results of this study seem to confirm these findings, as the most frequent patterns of consonant sequences were found in the L-C pattern. The L-C pattern was also the most frequently found variegated pattern in the BP-adapted CDI. The frequency of the D$\mathrm{C}$ pattern in these children's data may reflect the relative frequency of dorsals in the ambient language, judging from its occurrence in the BP-adapted CDI database as well. In this instance, the relative frequency of L-C sequences matches English children's patterns (Davis et al., 2002). The secondary effect of early appearance of D-C sequences may potentially be due to an effect of dorsal frequency in the ambient language on earliest place diversification in consonant sequences.

\section{Summary}

The predominant patterns in this study of two BP learning children from 12-36 months are similar to production patterns noted across other studies of this period of acquisition. Labials and coronals are prominent, as are low and mid front vowels. High vowels found in the BP children's productions and in the BP-adapted CDI targets may be lexical effects related to the use of diminutives. $\mathrm{CV}$ is the most frequent syllable type and reduplication occurs with higher frequency in the early period, as has been frequently noted in other studies. In addition, use of L-C in variegated sequences was confirmed in both children as well as in the BP-adapted CDI.

However, evidence of differences from data reported generally for this period were noted in the higher relative frequency of dorsals, predominance of multisyllabic over monosyllabic word forms, and in phone types found in syllable offset position. All are consistent with BP phonology. The presence of these areas of match with the ambient language not reported in other studies of early acquisition suggests that similarity in patterns across languages do not tell the entire story in the early stages of speech acquisition. However, a word of caution is in order in evaluating the general nature of these results. The influence of language input versus production influences may not be easily separable, as ease of articulation could be a prominant motivation for sound patterns in languages as well as in infants learning languages. However, in these earliest word forms, evidence of ambient language influences appears to be present and must be accounted for in fully understanding the nature of early acquisition in these two BP children.

Received: February 4, 2000; revised manuscript received: July 25, 2001; accepted: January 11, 2002 


\section{References}

ALBANO, E. (1993). Programa Listas - Banco de Dados do Minidicionário Aurélio. [Program List - Databank of the Aurelio Minidictionary]. LAFAPE: UNICAMP.

ALBANO, E., MOREIRA, A., AQUINO, P., SILVA, H., \& KAKINOHANA, R. (1995). Segment frequency and word structure in Brazilian Portuguese. Proceedings of the XII Congress of Phonetic Sciences, Stockholm, Sweden, 3, 346-349.

BOYSSON-BARDIES, B., SAGART, L., \& BACRI, N. (1981). Phonetic analysis of late babbling: A case study of a French child. Journal of Child Language, 8, 511-524.

BOYSSON-BARDIES, B., \& VIHMAN, M. M. (1991). Adaptation to language: Evidence from babbling and first words in four languages. Language, 67(2), 297-319.

BOYSSON-BARDIES, B., VIHMAN, M. M., ROUG-HELLICHIUS, L., DURAND, C., LANDBURG, I., \& ARAO, F. (1992). Material evidence of infant selection from the target language. In C. Ferguson, L. Menn, and C. Stoel-Gammon, Phonological Development. 369-392. York Press: Parkton.

CAGLIARI, L. C. (1981). Elementos de Fonética do Português Brasileiro. [Phonetic Elements of Brazilian-Portuguese]. Unpublished Thesis of "Livre Docência". Universidade Estadual de Campinas, São Paulo.

CÂMARA, J. M. (1972). The Portuguese language: History and structure. Chicago: University of Chicago Press.

CASTILHO, A., \& PRETTI, D. (1986). A linguagem falada culta na cidade de São Paulo [A wellknown language dialect of the city of Sao Paulo]. São Paulo: T. A Queiroz.

DAVIS, B. L., \& MACNEILAGE, P. F. (1990). The acquisition of correct vowel production: A quantitative case study. Journal of Speech and Hearing Research, 33, 16-27.

DAVIS, B. L., \& MACNEILAGE, P. F. (1994). Organization of babbling: A case study. Language \& Speech, 37 (4), $341-355$.

DAVIS, B. L., \& MACNEILAGE, P. F. (1995). The articulatory basis of babbling, Journal of Speech, Language, and Hearing Research, 38, 1199-1211.

DAVIS, B. L., \& MACNEILAGE, P. F. (2000). An embodiment perspective on the acquisition of speech perception, Special Issue, Phonetica, 57, 229-241.

DAVIS, B. L., MACNEILAGE, P. F., \& MATYEAR, C. L. (2002). Organization of serial complexity in speech production: A comparison of phonetic and phonological approaches to first word production. Phonetica, 59, 75-107.

FENSON, L., DALE, P., REZNICK, D., BATES, E., HARTUNG, J., PETHICK, S., \& REILLEY, J. (1992). MacArthur Communicative Development Inventory, San Diego, CA: Singular Publishing Group.

FERREIRA, A. (1977). Minidictionario Aurelio, [Aurelio Minidictionary]. Rio De Janeiro: Nova Frontiera.

GILDERSLEEVE-NEUMANN, C. E. (2001). Constraints on infant speech acquisition: A crosslanguage perspective. Unpublished doctoral dissertation, The University of Texas at Austin, Austin, TX.

GILDERSLEEVE-NEUMANN, C. E., \& DAVIS, B. L. (1998). Production versus ambient language influences on speech development in Quichua. Presentation at the American Speech, Language, and Hearing Association Convention, San Antonio, TX.

GILDERSLEEVE-NEUMANN, C. E., DAVIS, B. L., \& MACNEILAGE, P. F. (2000). Contingencies governing production of fricatives, affricates and liquids in babbling. Applied Psycholinguistics, 21, 341-363.

HEAD, B. (1964). A comparison of the segmental phonology of Lisbon and Rio de Janeiro. Unpublished doctoral dissertation, The University of Texas at Austin, Austin, TX.

HERNANDORENA, C. (1988). Uma proposta de análise de desvios fonológicos através de traços distintivos [A proposal to analyze diverse phonological patterns across dictinctive features]. Dissertação de Mestrado. Porto Alegre: Pontifícia Universidade do Rio Grande do Sul. 
HERNANDORENA, C. (1994). Uma leitura auto-segmental das substituições consonantais na aquisiçào do Português [An autosegmental analysis of consonant substitutions in acquisition of Portuguese]. UFBA, Estudos Lingüisticos e Literários, 17, 23-32.

HERNANDORENA, C. (1999). Tendências dos estudos de aquisição da fonologia do português brasileiro: A pertinência dos modelos gerativos [Patterns in acquisition of phonology of Brazilian Portuguese: Relevence to generative models]. Letras de Hoje, 117, 41-64.

INGRAM, D. (1974). Fronting in child phonology. Journal of Child Language, 1, 233-241.

INGRAM, D. (1981/2). The emerging phonological system of an Italian-English bilingual child. Journal of Italian Linguistics, 95-113.

INGRAM, D. (1988). The acquisition of word initial [v]. Language and Speech, 31, 77-85.

JACKSON-MALDONADO, D., THAL, D., MARCHMAN, V., BATES, E., \& GUITERREZCLELLEN, V. (in press). Early lexical development of Spanish-speaking children and toddlers. Journal of Child Language.

JAKOBSON, R. (1968). Child language, aphasia, and phonological universals. The Hague: Mouton.

KENT, R. D. (1994). Reference manual for communicative sciences and disorders. Austin, Texas: PRO-ED.

KENT, R. D., \& BAUER, H. R. (1985). Vocalizations of one-year-olds. Journal of Infant Language, 12, 491-526.

LABOV, W., \& LABOV, T. (1978). The phonetics of cat and mama. Language, 54(4), 816-852.

LAMPRECHT, R. (1986). Os processos nos desvios fonológicos evolutivos [Processes in the development of phonology]. Dissertação de Mestrado. Porto Alegre: Pontifícia Universidade do Rio Grande do Sul.

LAMPRECHT, R. (1990). Perfil da aquisição normal da fonologia do Português: Descrição longitudinal de 12 crianças: 2:9 a 5:5 [A profile of normal acquisition of the phonology of Portuguese: Longitudinal description of 12 children: 2:9 to 5:5]. Tese de Doutorado. Porto Alegre: Pontifícia Universidade do Rio Grande do Sul.

LAMPRECHT, R. (1999a). Aquisição da Linguagem: Questões e análises [Acquisition of language: Questions and analyses]. Porto Alegre: EDIPUCRS, 65-80.

LAMPRECHT, R. (1999b). Diferenças no ranqueamento de restrições como origem de diferenças na aquisição fonológica [Differences in ranking of restrictions similar to differences in the acquisition of phonology]. Letras de Hoje, 117, 65-82.

LEOPOLD, W. F. (1947). Speech development of a bilingual child: A linguist's record. Vol. 2: Sound learning in the first two years. Evanston, Ill.: Northwestern University Press.

LEVITT, A., \& UTTMAN, J. G. (1992). From babbling towards the sound systems of English and French: A longitudinal case study. Journal of Child Language, 19, 19-49.

LIEBERMAN, P. (1980). On the development of vowel production in young children, In YeniKomshian, G., Kavanaugh, J. F., \& Ferguson, C. A. (Eds.), Child Phonology: Volume 1; Production, New York: Academic Press.

LOCKE, J. (1983). Phonological acquisition and language change. New York: Academic Press.

MACKEN, M. A. (1992). Where's phonology? In C. A. Ferguson, L. Menn, \& C. Stoel-Gammon, (Eds.), Phonological development: Models, research, implications. Timonium, MD: York Press.

MACNEILAGE, P. F., \& DAVIS, B. L. (1990). Acquisition of speech production: Achievement of segmental independence. In W. I. Hardcastle, \& A. Marchal, (Eds.), Speech production and speech modeling, 55-68. The Netherlands: Dordrecht.

MACNEILAGE, P. F., \& DAVIS, B. L. (1993). A motor learning perspective on speech and babbling. In B. Boysson-Bardies, S. Schoen, P. Jusczyk, P. MacNeilage, \& J. Morton, (Eds.), Changes in speech and face processing in infancy: A glimpse at developmental mechanisms of cognition, 341-352. Dordredcht, The Netherlands: Kluwer.

MACNEILAGE, P. F., \& DAVIS, B. L. (2000). Origin of the internal structure of word forms, Science, 288, 527-531. 
MACNEILAGE, P. F., DAVIS, B. L., KINNEY, A., \& MATYEAR, C. L. (2000a). The motor core of speech: A comparison of serial organization patterns in infants and languages. Invited submission to Special Millennium Issue. Child Development, 71(1), 153-163.

MACNEILAGE, P. F., DAVIS, B. L., \& MATYEAR, C. L. (1997). Phonetic regression in first words? Speech Communication, 22, 269-277.

MACNEILAGE, P. F., DAVIS, B. L., KINNEY, A., \& MATYEAR, C. L., (2000b). Origin of speech output complexity in infants and in languages. Psychological Science, 459-460.

MENN, L. (1983). Development of articulatory, phonetic, and phonological capabilities. In L. Butterworth, Development, writing, and other processes, 4-50. New York: Academic Press.

OLLER, D. K., \& EILLERS, R. E. (1982). Similarity of babbling in Spanish- and Englishlearning babies. Journal of Child Language, 9, 565-577.

PARADIS, C., \& PRUNET, J. (1991). The special status of coronals: Internal and external evidence. San Diego: Academic Press.

PYE, C., INGRAM, D., \& LIST, H. (1987). A comparison of initial consonant acquisition of English and QuichÈ. In K. E. Nelson, \& A. van Kleeck, (Eds.), Children's Language, 175-190. Hillsdale, N J: Lawrence Erlbaum.

ROUG, L., LANDBURG, I., \& LUNDBURG, L. J. (1989). Phonetic development in early infancy: A study of four Swedish children during the first 18 months of life. Journal of Child Language, 16, 19-40.

STOEL-GAMMON, C. (1985). Phonetic inventories, 15-24 months: A longitudinal study. Journal of Speech and Hearing Research, 28, 505-512.

TEIXEIRA, E. R. (1980). A study of articulation testing with special reference to Portuguese. M. Phil. Thesis. University College-University of London. London: England.

TEIXEIRA, E. R. (1982). A Emergência do Sistema Fonológico em Português: Um Estudo Segmental da Pré-fala [Emergence of the phonological system of Portuguese: A study of prelinguistic segments]. Anais do VII Encontro Nacional de Lingüística. Rio de Janeiro, PUC/RJ, 72-90.

TEIXEIRA, E. R. (1984). O Exame Fonético-fonológico [The examination of phoneticsphonology]. Journal Brasileiro de Reabilitação Vocal. Niteroi, RJ, 13, $23-28$.

TEIXEIRA, E. R. (1985). The acquisition of phonology in cases of phonological disability in Portugese children. Unpublished doctoral dissertation. University College - University of London. London, U.K.

TEIXEIRA, E. R. (1991). Perfil do Desenvolvimento Fonológico em Português [Profile of development of phonology in Portuguese]. (PDFP.) Estudos Lingüísticos e Literários, Salvador, 12, 64-73.

TEIXEIRA, E. R. (1997). “The MacArthur Inventory (CDI) Adapted to Brazilian Portuguese: Analysis of the early sound patterns of children's targets" - Lecture presented to Speech Production Lab, The University of Texas at Austin, Austin, TX.

TEIXEIRA, E. R., DOURADO, L., SILVA, M. E., \& QUEIROZ, R. C. (1991). A Eliciação de Amostras Fonológicas [Elicitation of phonological samples]. Progress Report of the Project A Aquisição da Fonologia por Falantes do Português. UFBA.

TEIXEIRA, E. R., \& SILVA, C. T. (1999). Contagem de Freqüência da Ocorrência dos Padrões Silábicos em Português [Frequency counts of the occurrence of standard syllables of Portuguese]. In Resumos da VII Jornada de Estudos Lingüísticos do Nordeste (GELNE). Universida de Federal do Ceará, 318.

VIHMAN, M. M. (1996). Phonological development: The origins of language in the child. Oxford, England: Basil Blackwell.

VIHMAN, M. M., FERGUSON, C. E., \& ELBERT, M. (1986). Phonological development from babbling to speech: Common tendencies and individual differences. Applied Psycholinguistics, 7, 3-40. 
VIHMAN, M. M., MACKEN, M., MILLER, R., SIMMONS, H. (1985). From babbling to speech: A reassessment of the continuity issue. Language, 61, 397-445.

VOGEL, I. (1975). One system or two: An analysis of a two-year old Romanian-English bilingual's phonology. Papers and Reports on Child Language Development, 9, 43-62.

YAVAS, M. (1985). Desvios fonológicos nas crianças: Implicações da lingüística [Impaired phonology of children: Implications for language]. Letras de Hoje, 18(4), 77-130.

ZMARICH, C., \& LANNI, R. A. (1998). Phonetic and acoustic study of babbling in an Italian infant. Proceedings of the 5th International Conference on Spoken Language Processing, 1103-1104, Sydney, Australia. 
Copyright $\odot 2003$ EBSCO Publishing 